OPEN ACCESS

Edited by:

Ahmed S. BaHammam, King Saud University, Saudi Arabia

Reviewed by:

Thomas Penzel,

Charité Universitätsmedizin Berlin

Germany

Liborio Parrino,

Università degli Studi di Parma, Italy

*Correspondence:

Hanna A. Hensen

h.hensen@neura.edu.au

Specialty section:

This article was submitted to

Sleep and Chronobiology,

a section of the journa

Frontiers in Neurology

Received: 10 November 2017 Accepted: 22 December 2017

Published: 15 January 2018

Citation:

Hensen HA, Krishnan AV and Eckert DJ (2018) Sleep-Disordered

Breathing in People with

Multiple Sclerosis: Prevalence,

Pathophysiological Mechanisms, and Disease Consequences.

Front. Neurol. 8:740

doi: 10.3389/fneur.2017.00740

\section{Sleep-Disordered Breathing in People with Multiple Sclerosis: Prevalence, Pathophysiological Mechanisms, and Disease Consequences}

\author{
Hanna A. Hensen ${ }^{1,2 *}$, Arun V. Krishnan ${ }^{3}$ and Danny J. Eckert ${ }^{1,2}$ \\ ${ }^{1}$ Neuroscience Research Australia (NeuRA), Sydney, NSW, Australia, ${ }^{2}$ School of Medical Sciences, University of New South \\ Wales, Sydney, NSW, Australia, ${ }^{3}$ Prince of Wales Clinical School, University of New South Wales, Sydney, NSW, Australia
}

Sleep problems are common in people with multiple sclerosis (MS). Reported prevalence rates of sleep-disordered breathing (SDB) vary between 0 and $87 \%$. Differences in recruitment procedures and study designs likely contribute to the wide variance in reported prevalence rates of SBD in MS. This can make attempts to compare SDB rates in people with MS to the general population challenging. Little is known about the pathophysiological mechanisms that contribute to SDB in people with MS or whether MS contributes to SDB disease progression. However, compared to the general obstructive sleep apnea (OSA) population, there are clear differences in the clinical phenotypes of SDB in the MS population. For instance they are typically not obese and rates of SDB are often comparable or higher to the general population, despite the high female predominance of MS. Thus, the risk factors and pathophysiological causes of SDB in people with MS are likely to be different compared to people with OSA who do not have MS. There may be important bidirectional relationships between SDB and MS. Demyelinating lesions of MS in the brain stem and spinal cord could influence breathing control and upper airway muscle activity to cause SDB. Intermittent hypoxia caused by apneas during the night can increase oxidative stress and may worsen neurodegeneration in people with MS. In addition, inflammation and changes in cytokine levels may play a key role in the relationship between SDB and MS and their shared consequences. Indeed, fatigue, neurocognitive dysfunction, and depression may worsen considerably if both disorders coexist. Recent studies indicate that treatment of SDB in people with MS with conventional first-line therapy, continuous positive airway pressure therapy, can reduce fatigue and cognitive impairment. However, if the causes of SDB differ in people with MS, so too may the optimal therapy. Thus, many questions remain concerning the relationship between these two disorders and the underlying mechanisms and shared consequences. Improved understanding of these factors has the potential to unlock new therapeutic targets.

\footnotetext{
Keywords: sleep disorders, sleep apnea, obstructive, central, pathophysiology, fatigue, multiple sclerosis, cognition

Abbreviations: BMI, body mass index; EDSS, expanded disability status scale; ESS, Epworth sleepiness scale; FSS, fatigue severity scale; CPAP, continuous positive airway pressure; CSA, central sleep apnea; MFIS, modified fatigue impact scale; MRI, magnetic resonance imaging; MS, multiple sclerosis; OSA, obstructive sleep apnea; PSG, polysomnography; SDB, sleepdisordered breathing.
} 


\section{INTRODUCTION}

Understanding the potential link between sleep disruption and multiple sclerosis (MS) due to a sleep disorder or other MS disease-related causes is important. Recent studies have demonstrated that "poor sleep" is more common in people with MS compared to the general population $(1,2)$. Poor sleep can worsen quality of life and may contribute to the frequently experienced consequences of MS including fatigue and impaired neurocognitive function. Disrupted sleep may also contribute to MS disease progression (3-6). Potential disease-related contributors to sleep disruption in people with MS include symptoms such as pain, spasms, bladder dysfunction, or anxiety. However, sleep disorders such as insomnia, restless legs syndrome, and sleep-disordered breathing (SDB) have also been documented in MS $(7,8)$. Nonetheless, it remains uncertain if sleep disorders are more common in people with MS compared to the general population (9). This review focuses on SDB in MS. A summary of what is known regarding its prevalence, potential underlying mechanisms and links between the consequences of MS and SBD and how these may further perpetuate disease severity are discussed.

The estimated prevalence of SDB in middle-aged adults in the community ranges between 10 and $50 \%$ in men and 3 and $20 \%$ in women (10-12). Untreated SDB is associated with multiple adverse consequences including poor sleep quality, excessive daytime sleepiness, cognitive impairment, increased risk of motor vehicle accidents, and adverse cardiovascular outcomes (13-15). Recent data on the prevalence of SDB in MS are conflicting (16-19). Thus, it remains uncertain if SDB is more common in MS than in the general population. However, it is clear that MS and SDB have shared consequences such as fatigue, neurocognitive impairment, and depression which may contribute to increased morbidity. As will be discussed, there are also bidirectional pathophysiological pathways that may contribute to disease progression for both disorders $(6,20,21)$.

Sleep-disordered breathing and other sleep disorders are often underdiagnosed in MS $(7,22)$. This is possibly due to the fact that fatigue is generally accepted as being an "intrinsic" symptom of the disease rather than due to other potentially contributing causes such as sleep disruption (23). Thus, the treating clinician might be less likely to refer a patient with MS for polysomnography (PSG) compared to a person without MS. To what extent SDB contributes to the fatigue, neurocognitive impairment and disease progression in people with MS is not known. However, treating SDB may improve multiple aspects of MS. Recent studies that have included a relatively small number of participants have highlighted the potential beneficial role of treatment of SDB with continuous positive airway pressure (CPAP) to reduce fatigue in people with MS $(24,25)$.

In this review, current knowledge regarding the following key questions are addressed: In people with MS, how common is SDB? What are the risk factors and the pathophysiological causes? How will treatment influence key outcomes such as fatigue, neurocognitive function, balance, and disease severity/ progression?

\section{HOW COMMON IS SDB IN MS?}

Sleep studies in people with MS show conflicting results with regard to the prevalence of SDB. Indeed, the reported prevalence varies between 0 and $87 \%(6,7,16-19,24-35)$. A summary of the studies is shown in Tables $\mathbf{1}$ and $\mathbf{2}$. Table $\mathbf{1}$ highlights studies with objective sleep data (i.e., PSG or equivalent) and Table 2 covers studies with subjective data (i.e., questionnaires).

The variability in SDB prevalence between PSG studies in people with MS (0-87\%) can be explained by differences in study design, study population and methodology. Most of the studies were not designed to measure the prevalence of SDB per se. Some studies are retrospective (35), or included only fatigued patients $(16,19,30)$. The study populations vary greatly in characteristics such as age, disability level, body mass index (BMI), and female to male ratio. Regarding methodology the studies used different recording equipment and respiratory event scoring criteria. PSG technology has advanced significantly in recent years leading to increased sensitivity to detect respiratory events. The American Academy of Sleep Medicine scoring criteria have also been modified several times which have influenced respiratory event and SDB thresholds $(36,37)$.

The estimated prevalence of SDB based on questionnaire studies is more consistent and varies between 36 and $56 \%$ (7, 22, $32,33)$. However, these data are somewhat difficult to interpret as they represent the proportion of people with a high risk of obstructive sleep apnea (OSA) rather than direct objective assessment. It is also unclear whether current OSA screening tools, such as the STOPBANG (38) and Berlin questionnaires (39), are appropriate in the MS population. Indeed, they were designed and validated to assess OSA risk in the general non-MS population and have not been validated in people with MS. Nonetheless, a positive STOPBANG screening (a score of 3 or more out of a possible 8 ) has a positive predictive value of between 75 and $85 \%$ to detect OSA in the general population $(38,40)$. If this is similar in the MS population, these studies $(7,22,32,33)$ indicate a high prevalence of OSA. However, these questionnaires may not be accurate in the MS population because tiredness plays a major role in both questionnaires. These questions may confound the ability to detect sleep-specific consequences in the context of MS where disease-related symptoms of fatigue and tiredness are common. Indeed, while fatigue and sleepiness are separate constructs these aspects may be difficult for some people with MS to separate in OSA screening questionnaires. Additionally, these questionnaires are based on well-known risk factors for OSA in the general population. However, it is uncertain whether these risk factors play the same key roles in the development of SDB in people with MS. Accordingly, studies that combine questionnaire with PSG data are needed to define the accuracy of these questionnaires in the MS population. Additional knowledge about MS specific risk factors for SDB is also required as outlined below.

In summary, data from studies conducted over the past 20 years indicate that SDB is common in MS but the varied study designs and populations tested make it challenging to make direct comparisons with population based studies in the general community. 


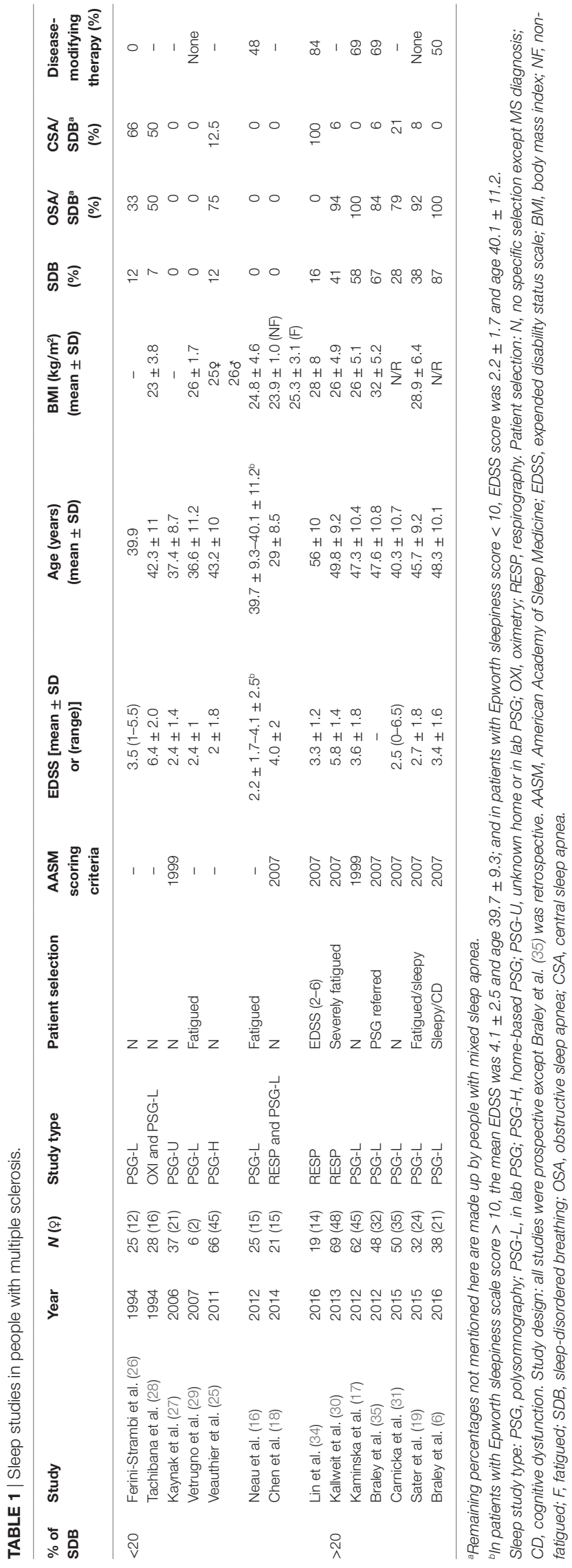

\section{WHAT ARE POSSIBLE RISK FACTORS FOR SDB IN MS?}

In order to determine possible risk factors for SBD in MS, we have separated PSG studies into two groups: (1) studies with a lower than 20\% prevalence of SDB and (2) studies with a higher than $20 \%$ prevalence of SDB (Table 1). In the subsequent section, we compare these groups and individual studies by known risk factors for SDB including: age, BMI, sex, and the MS-specific expanded disability status scale (EDSS) score.

\section{Age}

The mean age of the participants in the studies that detected a high prevalence of SDB is typically 45 years or above with the exception of the Carnicka et al. (31) study in which the mean age was 40 years (Figure 1). Conversely, in the lower prevalence studies the mean age was below 43 years in all cases with the exception of our recent pilot study in which the mean age was 50 years (34). Thus, similar to the general population $(11,41)$, increasing age appears to be risk factor for SDB in the MS population.

However, based on the available knowledge, it is not possible to distinguish if the increasing age causes SDB via the same mechanisms in the general versus MS population or whether MS specific disease duration factors are involved.

\section{Body Habitus}

While not all SDB studies in MS provide BMI data, in general, group mean BMI is less (BMI $23-28 \mathrm{~kg} / \mathrm{m}^{2}$ ) in studies with a low prevalence compared to those with a higher prevalence of SDB (BMI $26-32 \mathrm{~kg} / \mathrm{m}^{2}$ ) (Figure 2). Thus, similar to the general population (42), elevated BMI appears to be a risk factor in the MS population. However, with the exception of the Braley et al. study (35), the mean BMI for all of the MS studies is under $30 \mathrm{~kg} / \mathrm{m}^{2}$. Indeed, in the studies of Kallweit et al. and Kaminska et al., the average BMI is $26 \mathrm{~kg} / \mathrm{m}^{2}$, but the prevalence of SDB is 62 and $69 \%$, respectively $(17,30)$. This is clearly very high for a non-obese population. Thus, while BMI still appears to be a risk factor for SDB in the MS population, many people with MS who have SDB have much lower BMI's than the typical OSA patient population. Thus, the pathophysiological causes of OSA are likely to be quite different as outlined below.

\section{Sex Differences}

In the general population, SDB is two to three times more common in men compared to women (43). MS on the other hand is more common in women (3:1). Thus, almost all of the populations in which polysomnographs have been performed involve more women than men. Thus, it is important to consider the female to male ratios when interpreting the prevalence of SDB in MS. Unfortunately, most studies do not specify the prevalence of SDB by gender. However, in the two studies that do $(25,30)$, the prevalence of SDB is higher in men compared to women. In the Kallweit et al. study, the prevalence was 33\% in women and $60 \%$ in men ( $41 \%$ overall); and in the Veauthier et al. study, $11 \%$ of women and $14.2 \%$ of men (12\% overall) had SDB. Thus, while the number of studies is small, similar to the general population, male gender is a risk factor for SDB in the MS population. 
TABLE 2 | Screening questionnaires for OSA in people with multiple sclerosis.

\begin{tabular}{|c|c|c|c|c|c|c|c|c|}
\hline Study & $N$ (ㅇ) & $\begin{array}{l}\text { Patients } \\
\text { selection }\end{array}$ & $\begin{array}{c}\text { Disease } \\
\text { duration (years) } \\
\text { (mean } \pm \text { SD) }\end{array}$ & $\begin{array}{l}\text { Age (years) } \\
(\text { mean } \pm S D)\end{array}$ & $\begin{array}{l}\text { BMI }\left(k g / m^{2}\right) \\
(\text { mean } \pm S D)\end{array}$ & Questionnaire & $\begin{array}{l}\text { High risk of } \\
\text { OSA (\%) }\end{array}$ & $\begin{array}{c}\text { Official SDB } \\
\text { diagnosis } \\
(\%)\end{array}$ \\
\hline Dias et al. (32) & $103(74)$ & OPC & $11.7 \pm 8.9$ & $45.8 \pm 11.0$ & $28 \pm 6.5$ & STOPBANG & $42(28 \%, 76$ ðે) & 2 \\
\hline Brass et al. (7) & $\begin{array}{c}2,375 \\
(1,917)\end{array}$ & $\begin{array}{l}\text { Membership } \\
\text { list MS society }\end{array}$ & $16.3 \pm 10.8$ & $54.7 \pm 12.4$ & $>25$ in $61 \%^{a}$ & $\begin{array}{l}\text { STOPBANG and } \\
\text { Berlin }\end{array}$ & $\begin{array}{l}\text { STOPBANG: } 37 \\
\text { Berlin: } 37\end{array}$ & 4 \\
\hline Braley et al. (22) & 195 (128) & OPC & $10.2 \pm 8.2$ & $47.1 \pm 12.1$ & $29.6 \pm 7.4$ & STOPBANG & 56 & 21 \\
\hline Ma et al. (33) & $231(135)$ & OPC & $4.9 \pm 2.2$ & $40.2 \pm 7.8$ & $24.8 \pm 4.6$ & STOPBANG & 36 & - \\
\hline
\end{tabular}

a Mean BMI not provided, only percentage of people with BMI above $25 \mathrm{~kg} / \mathrm{m}^{2}$ is available.

Patient selection: OPC, outside patient clinic; BMI, body mass index; SDB, sleep-disordered breathing; OSA, obstructive sleep apnea; high risk of OSA, >3 points on STOPBANG questionnaire or 2 positive categories on Berlin questionnaire.

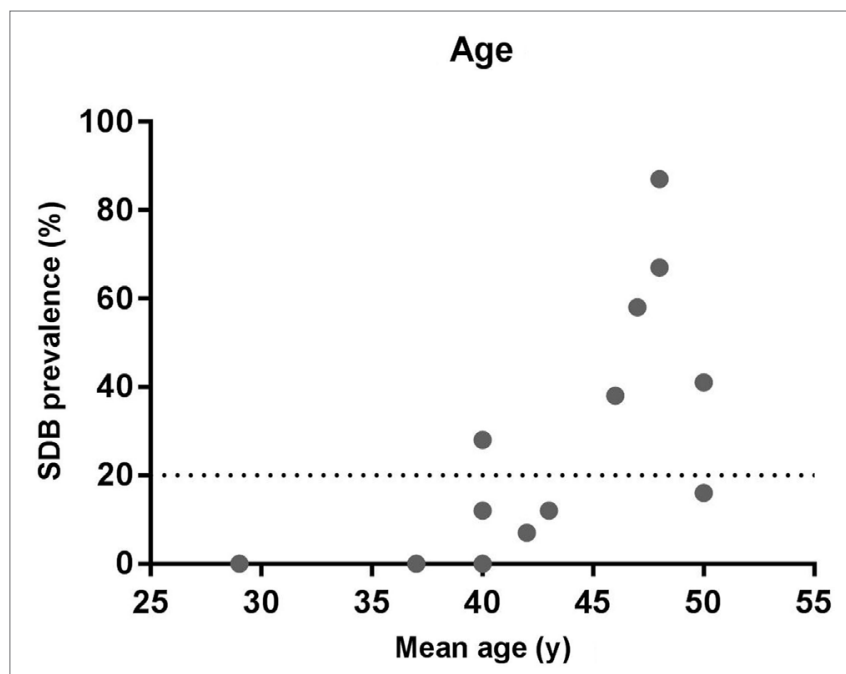

FIGURE 1 | Relationship between sleep-disordered breathing (SDB) prevalence and age. The data show the prevalence of SDB and the mean age from the studies listed in Table $\mathbf{1 .}$

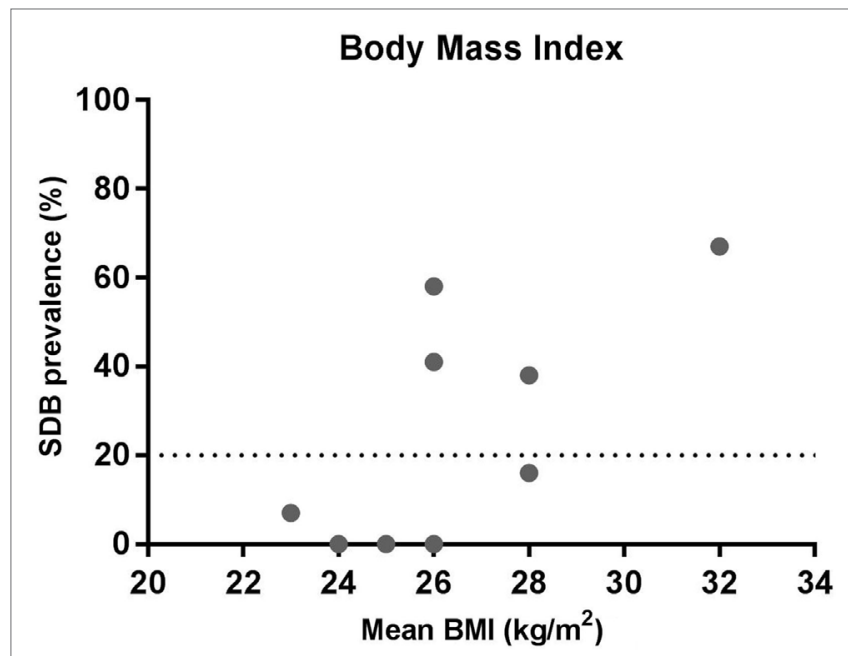

FIGURE 2 | Relationship between sleep-disordered breathing (SDB) prevalence and mean body mass index (BMI). The data show the prevalence of SDB and mean BMI from the studies listed in Table 1 where BMI was reported.

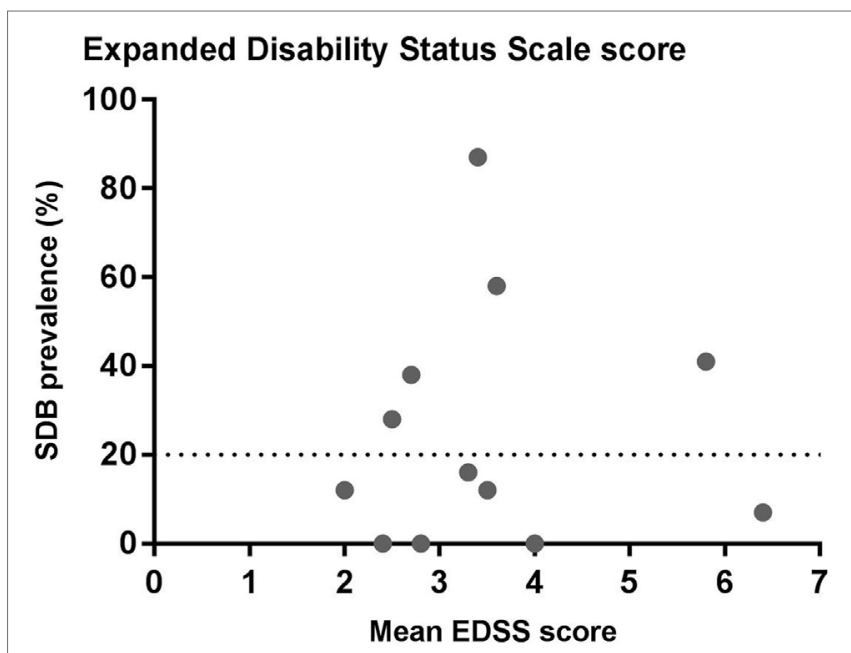

FIGURE 3 | Relationship between sleep-disordered breathing (SDB) prevalence and expanded disability status scale score (EDSS). The data show the prevalence of SDB and the mean EDSS scores from the studies listed in Table 1.

Nevertheless, it is noteworthy that some studies show such high rates of SDB even though the majority of the study populations are pre-menopausal women.

\section{MS Disability}

Multiple sclerosis disability is most commonly measured using the well-established EDSS score. EDSS varies from 0 (normal neurological examination) to 10 (death due to MS) (44) (Figure 3). There is substantial variation in mean EDSS scores in the studies that have investigated SBD in MS. There is no clear relationship between the prevalence of SDB and mean EDSS score based on the existing studies (Figure 3). However, this does not necessarily mean that MS severity does not influence SDB. The EDSS score is a good measure of clinical and functional disability, but it is heavily weighted toward motor and ambulatory deficits. Its correlation with lesion load and brain atrophy on magnetic resonance imaging (MRI) varies $(45,46)$. Thus, the extent to which other disease severity measures (e.g., lesion load and brain atrophy on MRI) influences the prevalence of SDB in people with MS is a valuable objective to assess in future studies. 
In summary, standard SDB risk factors (e.g., age and BMI) also appear to play a contributing role in people with MS. However, in general, people with MS and SDB tend not to be obese. The extent to which MS specific factors like disability and severity influence the prevalence of SDB is unclear.

\section{PATHOPHYSIOLOGICAL MECHANISMS OF SDB IN MS AND POTENTIAL BIDIRECTIONAL LINKS}

In this section, we attempt to address the following key questions: What are the causal pathways of SDB in people with MS? Are they the same as in the general population? How do SDB and MS influence each other?

To further explore these questions, a brief overview of the current understanding of the pathophysiology of SDB (OSA and central sleep apnea [CSA]) in the general population is highlighted below.

\section{Obstructive Sleep Apnea}

In OSA, there is an absence of airflow due to collapse of the upper airway, despite ongoing respiratory effort. Apneas and hypopneas are often associated with cortical arousals. The pathophysiological causes of OSA vary markedly between individuals. There are anatomical and non-anatomical contributors. The key pathophysiologic causes are: (1) an anatomically narrow or collapsible upper airway, (2) insufficient upper airway dilator muscle responsiveness during sleep, (3) a low respiratory arousal threshold, and (4) having an oversensitive ventilatory response system (high loop gain) (47-49). Inflammation state can also influence OSA $(50,51)$.

Major risk factors for OSA are aging, male sex, and obesity. The underlying mechanisms remain largely unclear, although other mediating mechanisms likely contribute via the pathophysiological causes highlighted above.

\section{Central Sleep Apnea}

In CSA, there is an absence of airflow, without respiratory effort. Thus, in CSA there is a fundamental issue with respiratory control during sleep. Briefly, the primary centers for central respiratory control are based in the pons and the medulla. These centers receive input from a variety of sources within the body including: the cortex (voluntary control), the limbic system (emotional stimuli), stretch receptors in the lungs, receptors for touch temperature and pain, receptors in muscles and joints, peripheral $\mathrm{O}_{2}, \mathrm{CO}_{2}$, and $\mathrm{H}^{+}$chemoreceptors located at the bifurcation of the carotid arteries, and central $\mathrm{CO}_{2}$ and $\mathrm{H}^{+}$chemoreceptors located at ventral surface of the medulla. Most of these inputs are capable to influence breathing during wakefulness, but are absent or decreased during sleep. Chemical control via the chemoreceptors is also decreased in sleep. However, it is the key regulator of breathing during sleep (52). There are several manifestations of CSA and the precise pathophysiological mechanisms vary, but in all instances unstable ventilatory drive is the principal underlying mechanism. There are three levels in the control of breathing during sleep where impairment could lead to CSA. There is (1) primary impaired central drive, for example caused by a lesion in the brain stem affecting the respiratory control center, (2) impaired output of central drive due to abnormalities located anywhere from upper motor neurons down to the respiratory muscles, for example caused by neuromuscular dysfunction, or (3) the central drive feedback loop is impaired, for example caused by prolonged blood circulation time in people with heart failure, resulting in a mismatch between arterial blood gas concentrations and respiratory controllers (53). Thus, impairment in one or more of these levels of the control of breathing can lead to CSA.

\section{Bidirectional Relationships}

To date, no studies have been conducted to characterize the phenotypic causes of SDB in people with MS. There are several possibilities and potential bidirectional relations that may create a vicious cycle between both disorders as highlighted in Figure 4 .

\section{MS As a Contributor to SDB}

Demyelinating lesions of MS in the brain stem and spinal cord could influence or evoke CSA via impairment of ventilatory drive. Lesions in the brain stem may influence primary central ventilatory drive centers directly or key components of the central breathing control feedback loop. Lesions in the spinal cord could also cause impairment of motor neurons that control the respiratory muscles to reduce ventilatory drive output. In accordance with this theory, Braley et al. have shown that the mean apnea hypopnea index and central apnea index of people with brain stem lesions in MS was significantly higher than controls or people with MS without known brain stem lesions (35). Furthermore, in the MS population studied by Lin et al., the only SDB that was detected was CSA and not OSA which is very rare in the non-MS population in the absence of key comorbidities such as heart failure. Other neurological disorders that affect brain stem function such as tumors $(54,55)$, hemorrhages, ischemia $(56,57)$, and Arnold-Chiari malformation (58), can also influence or cause SDB. However, in the studies listed in Table 1, the majority of people had OSA not CSA. This could be explained, because demyelinating lesions in the brain stem and spinal cord could also result in impaired upper airway muscle responsiveness and an unstable ventilatory response system, both of which contribute to OSA. Thus, demyelinating lesions in the brain stem and spinal cord are potentially important contributors to SDB in MS.

Second, inflammation in MS may also play a role in the occurrence of SDB. MS is an autoimmune disorder associated with changes in cytokine levels (59). How proinflammatory cytokines influence SDB is not known. However, systemic cytokine levels of TNF-a, IL-6, C-reactive protein, IL-1b, reactive oxygen species, and adhesion molecules are increased in people with OSA $(50,60)$. In MS, levels of TNF- $\alpha$, IL- 6 , and IL- $1 b$ amongst others are also elevated. Anti-inflammatory therapy with entracept (a TNF $\alpha$ antagonist) can improve OSA severity in the general population (51). This suggests that disease-modifying therapy with anti-inflammatory agents used in MS may also have a beneficial effect on OSA. However, to our knowledge there have been no studies conducted to investigate the potential relationship between inflammation in SDB and MS. 


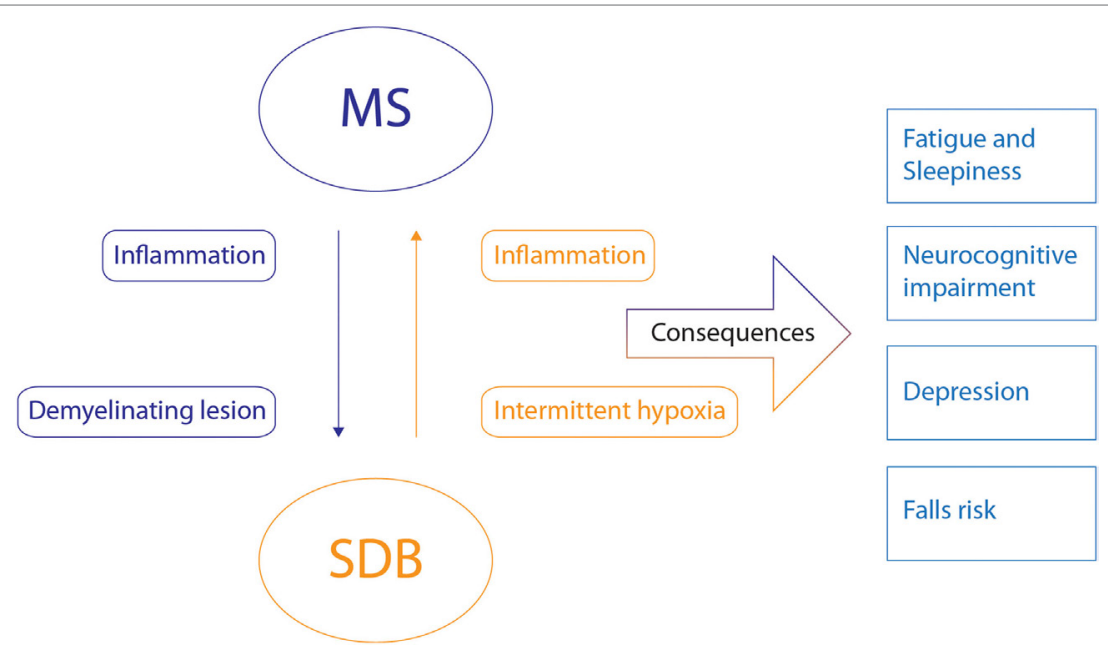

FIGURE 4 | Potential bidirectional relationships between multiple sclerosis (MS) and sleep-disordered breathing (SDB) and their shared consequences. The potential bidirectional pathophysiological relationship between MS and SDB is indicated by the arrows with the corresponding mechanisms. Inflammatory state and demyelinating lesions of MS may induce or influence SDB. Intermitted hypoxia and inflammation caused by SDB may also influence MS. The consequences that these disorders share are indicated on the right. The combination of these disorders will likely negatively influence these consequences.

\section{SDB As a Contributor to MS}

As highlighted, chronic inflammation is a feature of both SDB and MS. Thus, the proinflammatory state caused by SDB may interact with the inflammatory process taking place in MS and contribute to disease progression or relapse frequency. However, this theory has not been formally investigated.

The second factor that can play an important role in the progression of MS due to SDB is intermittent hypoxia. One of the potential factors attributed to lesion progression in MS is "virtual hypoxia," which is a state of reduced oxygen consumption and energy failure in conditions of normal blood and oxygen supply leading to cell death. "Virtual hypoxia" is caused by damaged mitochondria, likely attributed to chronic oxidative injury. Inflammation of the brain tissue drives microglia and macrophage activation, resulting in oxidative stress, causing mitochondrial injury, making it a vicious cycle of tissue destruction and energy failure $(61,62)$. When brain tissue is affected by "virtual hypoxia," additional intermittent hypoxia due to SDB may amplify neurodegeneration. Indeed, studies have shown that there are increased MS lesion loads in the "watershed" areas of the brain and spinal cord, which are areas that are on the boundaries between the blood supply of the cerebral arteries and therefore less well perfused and most vulnerable to reduced blood flow or reduced oxygen. This suggests that hypoxia may play an important role in lesion pathology (63). In addition, animal studies indicate that demyelination can be reduced or eliminated by increasing inspired oxygen to alleviate transient hypoxia (64). This progression of disease due to mitochondrial injury and energy failure is thought to play an especially important role in the progressive phase of the disease. Progressive MS is divided in primary progressive (being progressive from the moment of diagnosis) and secondary progressive (being progressive after the initial relapsing remitting phase). Progressive MS commonly affects the middle aged population (65). This is important since middle aged adults are at high risk of SDB. There are only few treatments available for the progressive phase of the disease and anti-inflammatory drugs yield little improvement (61). Thus, diagnosing SDB and effectively treating $\mathrm{SDB}$ to restore oxygenation in the brain may play a pivotal role in slowing progression in this phase of the disease. This is a priority for future research.

\section{SHARED CONSEQUENCES OF SDB AND MS}

Sleep-disordered breathing and MS have shared consequences, as shown in Figure 4. These consequences may be synergistic if both disorders are present. Important shared consequences include: fatigue/sleepiness, neurocognitive dysfunction, depression, and falls risk. Although not covered in this review, there may also be other shared links between cardiovascular risk, inflammation, SDB, and MS (66-68). Diagnosis and treatment of SDB in afflicted people with MS may help alleviate these common consequences as discussed below.

\section{Fatigue and Sleepiness}

Fatigue is a common symptom in MS. Indeed, fatigue is often the most debilitating symptom of MS and has a major impact on quality of life $(20,21,23,69)$. There have been multiple studies on fatigue in MS including various strategies on quantification, its potential origin and treatment. However, the pathophysiology still remains to a large extend unknown. Kos et al. (70) divided fatigue in MS into primary fatigue and secondary fatigue. Primary fatigue may be due to centrally mediated processes, like demyelination in the central nervous system and immune activity. Factors that may influence secondary fatigue are sleeping problems, pain, depression, reduced activity, psychological functioning, and medication use. 
It is important to note that fatigue and sleepiness are two distinct but potentially interrelated symptoms that often coexist. Chervin et al. have shown that patients with moderate to severe OSA report problems with fatigue, tiredness, and lack of energy more frequently than sleepiness $(57,61,62$, and 47\%) (71). Hossain et al. assessed 283 patients with sleep disorders and in this cohort $64 \%$ reported pathological fatigue without overlap of sleepiness and only $4 \%$ reported sleepiness without overlap fatigue. This suggests that fatigue and sleepiness can be independent manifestations of sleep disorders (72). The extent to which SDB plays a role in fatigue in MS has been assessed in several studies. Veauthier et al. studied $66 \mathrm{MS}$ patients who underwent PSG and completed the modified fatigue impact scale (MFIS) to quantify fatigue severity. There were eight patients with SDB, of which seven were fatigued, defined as a score $>45$ on the MFIS. The people with SDB also had higher scores on the MFIS compared to fatigued people without SDB (25). Kaminska et al. found a relationship between severe OSA (apnea hypopnea index $>30$ events/h sleep) and severe fatigue in people with MS. The mean fatigue severity scale (FSS) scores were also significantly higher in people with MS and severe OSA compared to those without severe OSA (17).

In addition, some studies have assessed the risk of OSA, using the STOPBANG questionnaire, and its relationship with fatigue. Dias et al. found a significant correlation in STOPBANG scores and FSS scores in males but not in females (32). Braley et al. demonstrated that OSA is a significant predictor of fatigue when adjusted for other clinical- and sleep-related factors for fatigue (22). Brass et al. demonstrated an odds ratio of a STOP BANG $>3$ to having a FSS $>36$ is 1.85 , consistent with an association between OSA and fatigue (7). Thus, it appears that SDB has a negative effect on fatigue in people with MS.

Fatigue is a very difficult symptom of MS to treat. All current therapies are either ineffective or only partially effective (73). To date, there have only been a few studies to examine whether treatment of SDB improves fatigue in MS. Kallweit et al. treated 6 MS patients with OSA with CPAP therapy for 6 months with a daily average adherence of $>5$ h per night. Measures of sleepiness with the Epworth sleepiness scale (ESS) and fatigue with the FSS were assed at baseline and after 6 months. The apnea hypopnea index decreased from 39 to 5 events/h sleep. ESS scores did not show any significant change (9.8-9.5), but there was a significant decrease in FSS scores from 5.8 to 4.8 . However, the FSS score remained pathologic $(>4)$ in all patients $(30)$. Cote et al. also treated MS patients with OSA with CPAP and compared ESS and FSS scores before and after 3 months of therapy. ESS scores decreased significantly with treatment from 8.9 to 5.4 and FSS scores decreased from 5.0 to 4.3 . However, this change was not statistically significant (24). Larger studies are needed in people with MS and SDB to quantify the effects of treatment on fatigue in people with MS.

\section{Neurocognitive Dysfunction}

In the general population, SDB can result in neuropsychological impairment $(15,74)$. Changes in brain structure have also been demonstrated in people with OSA and impaired cognitive function using imaging techniques $(75,76)$. Neuropsychological domains influenced by OSA include: attention/vigilance, executive function, and memory. The ethology of cognitive dysfunction in OSA is believed to be multifactorial with sleep fragmentation and hypoxemia as key contributors. These factors may have similar or greater effects in people with MS. Nocturnal hypoxia in OSA can cause neuroimaging and neuropathological abnormalities in regions of the cortex and axons that are similar to cognitive domains affected in MS (77). There has been only one study conducted to investigate the relationship between cognitive function and OSA in people with MS. Braley et al. assessed 38 MS patients from an outside patient clinic that asked about sleep or cognition during routine visits. Participants were evaluated by a neurologist, neuropsychologist and an overnight PSG was conducted. Cognitive function testing was performed using the validated 90-min battery, minimal assessment of cognitive function in MS. Regression models demonstrated an association between several components of neuropsychological function (attention and working memory) and oxygen desaturation index, minimum oxygen saturation, and respiratory disturbance index. An association between verbal memory and response inhibition and sleep quality parameters was also shown (6). Similar findings have been demonstrated in the general population $(78,79)$.

Cognitive function in people with MS and OSA could potentially be improved with CPAP therapy. Beneficial effects of CPAP on cognitive performance have been shown in the non-MS OSA population in some $(75,76)$ but not all studies $(74)$. Given that oxygen levels may play a key role in the decrease in cognitive function, oxygen therapy may also be beneficial, either indirectly via reductions in SDB or directly via restoration of oxygenation (80). Braley et al. have a randomized controlled trial on the effects of CPAP on cognitive function in MS patients with OSA that is currently underway (NCT02544373). The results will be of great importance to evaluate the potential need for early diagnosis of SDB and the influence of treatment on cognitive function. There are currently few options to improve cognitive function in MS. However, immunomodulatory therapy may slow and reverse MS-related cognitive dysfunction and have a positive effect on OSA severity in MS $(81,82)$.

\section{Depression}

Depression is common in people with MS, with an estimated annual prevalence of $20 \%$ and lifetime prevalence as high as $50 \%$ (83). Depression is more common in people with SDB compared to the general population. The estimated prevalence of depression in people from the general community who have OSA is between 17 and $22 \%$ and in clinical population studies ranges between 21 and $41 \%$ (84). For both disorders it is to a large extent unknown what their role is in the causation of depression. However, given the bidirectional relationship between sleep and the brain, it is likely that people with MS who experience sleep disruption due to SDB will be at higher risk of depression.

\section{Falls Risk}

Falls frequently occur in people with MS. Several studies have shown that $50-60 \%$ of people with MS report falling at least once in a 2- to 6-month period (85-87). Medical care is often required. Important factors that increase the risk of falling in people with 
MS are loss of balance, impaired gait, use of a walking aid, leg weakness, visual impairment, reduced cognitive function, and fatigue (88).

There is growing evidence that poor sleep and sleep disorders can increase falls risk in the elderly independent of other factors (89-91). Since factors that increase the risk of falling in elderly are to a large extend similar to the ones in MS (like reduced balance, visual impairment, cognitive decline, and the use of a walking aid), poor sleep might have an equivalent impact on people with MS. In young adults postural sway, a measure of balance, significantly increases after sleep deprivation $(92,93)$. Excessive daytime sleepiness defined as a score $>10$ on the ESS is also an independent risk factor for falls (94). Given that sleepiness is common in people with moderate to severe SDB, sleepiness due to SDB in people with MS may increase falls risk. There have only been a few studies that have examined the relationship between SDB and balance control. A recent study by Degache et al. noted an association between overnight hypoxia and postural instability (95). Two additional studies also showed an altered gait pattern in people with OSA compared to healthy controls $(96,97)$. The precise mechanism as to how falls risk increases due to poor sleep is unknown, but the combination of MS and SDB may have an additive effect in increasing the risk of falls. Therefore, given that $\mathrm{SDB}$ is a modifiable factor, treatment of SDB may reduce the risk of falling in people with MS.

\section{REFERENCES}

1. Boe Lunde HM, Aae TF, Indrevag W, Aarseth J, Bjorvatn B, Myhr KM, et al. Poor sleep in patients with multiple sclerosis. PLoS One (2012) 7(11):e49996. doi:10.1371/journal.pone.0049996

2. Bamer AM, Johnson KL, Amtmann D, Kraft GH. Prevalence of sleep problems in individuals with multiple sclerosis. Mult Scler (2008) 14(8):1127-30. doi:10.1177/1352458508092807

3. Merlino G, Fratticci L, Lenchig C, Valente M, Cargnelutti D, Picello M, et al. Prevalence of 'poor sleep' among patients with multiple sclerosis: an independent predictor of mental and physical status. Sleep Med (2009) 10(1):26-34. doi:10.10/j.sleep.2007.11.004

4. Attarian H. Importance of sleep in the quality of life of multiple sclerosis patients: a long under-recognized issue. Sleep Med (2009) 10(1):7-8. doi:10.1016/j.sleep.2008.02.002

5. Kaminska M, Kimoff RJ, Schwartzman K, Trojan DA. Sleep disorders and fatigue in multiple sclerosis: evidence for association and interaction. J Neurol Sci (2011) 302(1-2):7-13. doi:10.1016/j.jns.2010.12.008

6. Braley TJ, Kratz AL, Kaplish N, Chervin RD. Sleep and cognitive function in multiple sclerosis. Sleep (2016) 39(8):1525-33. doi:10.5665/sleep.6012

7. Brass SD, Li CS, Auerbach S. The underdiagnosis of sleep disorders in patients with multiple sclerosis. J Clin Sleep Med (2014) 10(9):1025-31. doi:10.5664/jcsm.4044

8. Manconi M, Ferini-Strambi L, Filippi M, Bonanni E, Iudice A, Murri L, et al. Multicenter case-control study on restless legs syndrome in multiple sclerosis: the REMS study. Sleep (2008) 31(7):944-52. doi:10.5665/sleep/31.7.944

9. Braley TJ, Boudreau EA. Sleep disorders in multiple sclerosis. Curr Neurol Neurosci Rep (2016) 16(5):50. doi:10.1007/s11910-016-0649-2

10. Heinzer R, Vat S, Marques-Vidal P, Marti-Soler H, Andries D, Tobback N, et al. Prevalence of sleep-disordered breathing in the general population: the HypnoLaus study. Lancet Respir Med (2015) 3(4):310-8. doi:10.1016/ S2213-2600(15)00043-0

11. Peppard PE, Young T, Barnet JH, Palta M, Hagen EW, Hla KM. Increased prevalence of sleep-disordered breathing in adults. Am JEpidemiol (2013) 177(9):1006-14. doi:10.1093/aje/kws342

12. Simpson L, Hillman DR, Cooper MN, Ward KL, Hunter M, Cullen S, et al. High prevalence of undiagnosed obstructive sleep apnoea in the general

\section{SUMMARY AND FUTURE RESEARCH DIRECTIONS}

It remains uncertain how common SDB is in people with MS. However, many of the existing studies indicate that it is quite common despite the female predominance and typical lack of obesity in the MS population. Understanding the mechanisms of SBD in people with MS for which there are multiple plausible possibilities, may provide novel targets for therapy. Given the shared links between the two disorders and supported by several initial studies, improvements in sleep by treating SDB has the potential to reduce the burden of several of the key shared consequences and may also reduce MS disease progression. These are all important topics for future research.

\section{AUTHOR CONTRIBUTIONS}

$\mathrm{HH}$ drafted the manuscript, and all authors provided important intellectual input and contributed to the final version.

\section{FUNDING}

AK and DE are supported by National Health and Medical Research Council of Australia Fellowships (1065663 and 1116942 respectively).

population and methods for screening for representative controls. Sleep Breath (2013) 17(3):967-73. doi:10.1007/s11325-012-0785-0

13. Teran-Santos J, Jimenez-Gomez A, Cordero-Guevara J. The association between sleep apnea and theriskoftrafficaccidents. Cooperative Group Burgos-Santander. N Engl J Med (1999) 340(11):847-51. doi:10.1056/NEJM199903183401104

14. McNicholas WT, Bonsigore MR; Management Committee of EU COST ACTION B26. Sleep apnoea as an independent risk factor for cardiovascular disease: current evidence, basic mechanisms and research priorities. Eur Respir J (2007) 29(1):156-78. doi:10.1183/09031936.00027406

15. Aloia MS, Arnedt JT, Davis JD, Riggs RL, Byrd D. Neuropsychological sequelae of obstructive sleep apnea-hypopnea syndrome: a critical review. J Int Neuropsychol Soc (2004) 10(5):772-85. doi:10.1017/S1355617704105134

16. Neau JP, Paquereau J, Auche V, Mathis S, Godeneche G, Ciron J, et al. Sleep disorders and multiple sclerosis: a clinical and polysomnography study. Eur Neurol (2012) 68(1):8-15. doi:10.1159/000335076

17. Kaminska M, Kimoff RJ, Benedetti A, Robinson A, Bar-Or A, Lapierre Y, et al. Obstructive sleep apnea is associated with fatigue in multiple sclerosis. Mult Scler (2012) 18(8):1159-69. doi:10.1177/1352458511432328

18. Chen JH, Liu XQ, Sun HY, Huang Y. Sleep disorders in multiple sclerosis in China: clinical, polysomnography study, and review of the literature. J Clin Neurophysiol (2014) 31(4):375-81. doi:10.1097/WNP.0000000000000067

19. Sater RA, Gudesblatt M, Kresa-Reahl K, Brandes DW, Sater PA. The relationship between objective parameters of sleep and measures of fatigue, depression, and cognition in multiple sclerosis. Mult Scler J Exp Transl Clin (2015) 1:1-8. doi:10.1177/2055217315577828

20. KruppLB,AlvarezLA,LaRoccaNG,ScheinbergLC. Fatigueinmultiplesclerosis. Arch Neurol (1988) 45(4):435-7. doi:10.1001/archneur.1988.00520280085020

21. Janardhan V, Bakshi R. Quality of life in patients with multiple sclerosis: the impact of fatigue and depression. J Neurol Sci (2002) 205(1):51-8. doi:10.1016/ S0022-510X(02)00312-X

22. Braley TJ, Segal BM, Chervin RD. Obstructive sleep apnea and fatigue in patients with multiple sclerosis. J Clin Sleep Med (2014) 10(2):155-62. doi: $10.5664 /$ jcsm. 3442

23. Krupp L. Fatigue is intrinsic to multiple sclerosis (MS) and is the most commonly reported symptom of the disease. Mult Scler (2006) 12(4):367-8. doi:10.1191/135248506ms1373ed 
24. Cote I, Trojan DA, Kaminska M, Cardoso M, Benedetti A, Weiss D, et al. Impact of sleep disorder treatment on fatigue in multiple sclerosis. Mult Scler (2013) 19(4):480-9. doi:10.1177/1352458512455958

25. Veauthier C, Radbruch H, Gaede G, Pfueller CF, Dorr J, Bellmann-Strobl J, et al. Fatigue in multiple sclerosis is closely related to sleep disorders: a polysomnographic cross-sectional study. Mult Scler (2011) 17(5):613-22. doi: $10.1177 / 1352458510393772$

26. Ferini-Strambi L, Filippi M, Martinelli V, Oldani A, Rovaris M, Zucconi M, et al. Nocturnal sleep study in multiple sclerosis: correlations with clinical and brain magnetic resonance imaging findings. J Neurol Sci (1994) 125(2):194-7. doi:10.1016/0022-510X(94)90035-3

27. Kaynak H, Altintas A, Kaynak D, Uyanik O, Saip S, Agaoglu J, et al. Fatigue and sleep disturbance in multiple sclerosis. Eur J Neurol (2006) 13(12):1333-9. doi:10.1111/j.1468-1331.2006.01499.x

28. Tachibana N, Howard RS, Hirsch NP, Miller DH, Moseley IF, Fish D. Sleep problems in multiple sclerosis. Eur Neurol (1994) 34(6):320-3. doi:10.1159/000117070

29. Vetrugno R, Stecchi S, Scandellari C, Pierangeli G, Sabattini L, D’Angelo R, et al. Sleep-wake and body core temperature rhythms in multiple sclerosis with fatigue. Neurophysiol Clin (2007) 118(1):228-34. doi:10.1016/j. clinph.2006.09.021

30. Kallweit U, Baumann CR, Harzheim M, Hidalgo H, Pohlau D, Bassetti CL, et al. Fatigue and sleep-disordered breathing in multiple sclerosis: a clinically relevant association? Mult Scler Int (2013) 2013:286581. doi:10.1155/2013/286581

31. Carnicka Z, Kollar B, Siarnik P, Krizova L, Klobucnikova K, Turcani P. Sleep disorders in patients with multiple sclerosis. J Clin Sleep Med (2015) 11(5):553-7. doi:10.5664/jcsm.4702

32. Dias RA, Hardin KA, Rose H, Agius MA, Apperson ML, Brass SD. Sleepiness, fatigue, and risk of obstructive sleep apnea using the STOP-BANG questionnaire in multiple sclerosis: a pilot study. Sleep Breath (2012) 16(4):1255-65. doi:10.1007/s11325-011-0642-6

33. MaS, RuiX, Qi P, Liu G, Yang J. Sleep disorders in patients with multiple sclerosis in China. Sleep Breath (2017) 21(1):149-54. doi:10.1007/s11325-016-1416-y

34. Lin M, Krishnan AV, Eckert DJ. Central sleep apnea in multiple sclerosis: a pilot study. Sleep Breath (2017) 21(3):691-6. doi:10.1007/s11325-016-1442-9

35. Braley TJ, Segal BM, Chervin RD. Sleep-disordered breathing in multiple sclerosis. Neurology (2012) 79(9):929-36. doi:10.1212/WNL.0b013e318266fa9d

36. American Academy of Sleep Medicine Task Force. Sleep-related breathing disorders in adults: recommendations for syndrome definition and measurement techniques in clinical research. Sleep (1999) 22(5):667-89. doi:10.1093/ sleep/22.5.667

37. Berry RB, Budhiraja R, Gottlieb DJ, Gozal D, Iber C, Kapur VK, et al. Rules for scoring respiratory events in sleep: update of the 2007 AASM Manual for the Scoring of Sleep and Associated Events. Deliberations of the Sleep Apnea Definitions Task Force of the American Academy of Sleep Medicine. J Clin Sleep Med (2012) 8(5):597-619. doi:10.5664/jcsm.2172

38. Chung F, Subramanyam R, Liao P, Sasaki E, Shapiro C, Sun Y. High STOP-Bang score indicates a high probability of obstructive sleep apnoea. Br J Anaesth (2012) 108(5):768-75. doi:10.1093/bja/aes022

39. Netzer NC, Stoohs RA, Netzer CM, Clark K, Strohl KP. Using the Berlin Questionnaire to identify patients at risk for the sleep apnea syndrome. Ann Intern Med (1999) 131(7):485-91. doi:10.7326/0003-4819-131-7-19991005000002

40. Farney RJ, Walker BS, Farney RM, Snow GL, Walker JM. The STOP-Bang equivalent model and prediction of severity of obstructive sleep apnea: relation to polysomnographic measurements of the apnea/hypopnea index. J Clin Sleep Med (2011) 7(5):459b-65b. doi:10.5664/JCSM.1306

41. Bixler EO, Vgontzas AN, Ten Have T, Tyson K, Kales A. Effects of age on sleep apnea in men: I. Prevalence and severity. Am J Respir Crit Care Med (1998) 157(1):144-8. doi:10.1164/ajrccm.157.1.9706079

42. Young T, Skatrud J, Peppard PE. Risk factors for obstructive sleep apnea in adults. JAMA (2004) 291(16):2013-6. doi:10.1001/jama.291.16.2013

43. Bixler EO, Vgontzas AN, Lin HM, Ten Have T, Rein J, Vela-Bueno A, et al. Prevalence of sleep-disordered breathing in women: effects of gender. Am J Respir Crit Care Med (2001) 163(3 Pt 1):608-13. doi:10.1164/ ajrccm.163.3.9911064

44. Kurtzke JF. Rating neurologic impairment in multiple sclerosis: an expanded disability status scale (EDSS). Neurology (1983) 33(11):1444-52. doi:10.1212/ WNL.33.11.1444
45. Poonawalla AH, Datta S, Juneja V, Nelson F, Wolinsky JS, Cutter G, et al. Composite MRI scores improve correlation with EDSS in multiple sclerosis. Mult Scler (2010) 16(9):1117-25. doi:10.1177/1352458510374892

46. Martinelli Boneschi F, Rovaris M, Comi G, Filippi M. The use of magnetic resonance imaging in multiple sclerosis: lessons learned from clinical trials. Mult Scler (2004) 10(4):341-7. doi:10.1191/1352458504ms1067rr

47. Eckert DJ, Malhotra A. Pathophysiology of adult obstructive sleep apnea. Proc Am Thorac Soc (2008) 5(2):144-53. doi:10.1513/pats.200707-114MG

48. Eckert DJ, White DP, Jordan AS, Malhotra A, Wellman A. Defining phenotypic causes of obstructive sleep apnea. Identification of novel therapeutic targets. Am J Respir Crit Care Med (2013) 188(8):996-1004. doi:10.1164/ rccm.201303-0448OC

49. Edwards BA, Eckert DJ, Jordan AS. Obstructive sleep apnoea pathogenesis from mild to severe: is it all the same? Respirology (2017) 22(1):33-42. doi:10.1111/resp.12913

50. Bergeron C, Kimoff J, Hamid Q. Obstructive sleep apnea syndrome and inflammation. J Allergy Clin Immunol (2005) 116(6):1393-6. doi:10.1016/j. jaci.2005.10.008

51. Vgontzas AN, Zoumakis E, Lin HM, Bixler EO, Trakada G, Chrousos GP. Marked decrease in sleepiness in patients with sleep apnea by etanercept, a tumor necrosis factor-alpha antagonist. J Clin Endocrinol Metab (2004) 89(9):4409-13. doi:10.1210/jc.2003-031929

52. Martins RT, Eckert DJ. Central sleep apnea due to other medical disorders. Sleep Med Clin (2014) 9(1):57-67. doi:10.1016/j.jsmc.2013.10.002

53. Eckert DJ, Jordan AS, Merchia P, Malhotra A. Central sleep apnea: pathophysiology and treatment. Chest (2007) 131(2):595-607. doi:10.1378/chest.06.2287

54. Manning HL, Leiter JC. Respiratory control and respiratory sensation in a patient with a ganglioglioma within the dorsocaudal brain stem. Am J Respir Crit Care Med (2000) 161(6):2100-6. doi:10.1164/ajrccm.161.6.9904087

55. Maiuri F, Esposito M. Positional and sleep dyspnoea due to posterior exophytic ependymoma of the medulla oblongata. J Neurol Neurosurg Psychiatry (2005) 76(6):804. doi:10.1136/jnnp.2004.050799

56. Brown DL, McDermott M, Mowla A, De Lott L, Morgenstern LB, Kerber KA, et al. Brainstem infarction and sleep-disordered breathing in the BASIC sleep apnea study. Sleep Med (2014) 15(8):887-91. doi:10.1016/j.sleep.2014.04.003

57. Duning T, Deppe M, Brand E, Stypmann J, Becht C, Heidbreder A, et al. Brainstem involvement as a cause of central sleep apnea: pattern of microstructural cerebral damage in patients with cerebral microangiopathy. PLoS One (2013) 8(4):e60304. doi:10.1371/journal.pone.0060304

58. Lam B, Ryan CF. Arnold-Chiari malformation presenting as sleep apnea syndrome. Sleep Med (2000) 1(2):139-44. doi:10.1016/S1389-9457(99)00004-0

59. Kallaur AP, Oliveira SR, Colado Simao AN, Delicato de Almeida ER, Kaminami Morimoto H, Lopes J, et al. Cytokine profile in relapsing-remitting multiple sclerosis patients and the association between progression and activity of the disease. Mol Med Rep (2013) 7(3):1010-20. doi:10.3892/mmr.2013.1256

60. Hatipoglu U, Rubinstein I. Inflammation and obstructive sleep apnea syndrome pathogenesis: a working hypothesis. Respiration (2003) 70(6):665-71. doi:10.1159/000075218

61. Mahad DH, Trapp BD, Lassmann H. Pathological mechanisms in progressive multiple sclerosis. Lancet Neurol (2015) 14(2):183-93. doi:10.1016/ S1474-4422(14)70256-X

62. Lassmann H. Demyelination and neurodegeneration in multiple sclerosis: the role of hypoxia. Ann Neurol (2016) 79(4):520-1. doi:10.1002/ana.24632

63. Holland CM, Charil A, Csapo I, Liptak Z, Ichise M, Khoury SJ, et al. The relationship between normal cerebral perfusion patterns and white matter lesion distribution in 1,249 patients with multiple sclerosis. J Neuroimaging (2012) 22(2):129-36. doi:10.1111/j.1552-6569.2011.00585.x

64. Desai RA, Davies AL, Tachrount M, Kasti M, Laulund F, Golay X, et al. Cause and prevention of demyelination in a model multiple sclerosis lesion. Ann Neurol (2016) 79(4):591-604. doi:10.1002/ana.24607

65. Ontaneda D, Fox RJ, Chataway J. Clinical trials in progressive multiple sclerosis: lessons learned and future perspectives. Lancet Neurol (2015) 14(2):208-23. doi:10.1016/S1474-4422(14)70264-9

66. Kent BD, Ryan S, McNicholas WT. Obstructive sleep apnea and inflammation: relationship to cardiovascular co-morbidity. Respir Physiol Neurobiol (2011) 178(3):475-81. doi:10.1016/j.resp.2011.03.015

67. Wens I, Dalgas U, Stenager E, Eijnde BO. Risk factors related to cardiovascular diseases and the metabolic syndrome in multiple sclerosis - a systematic review. Mult Scler (2013) 19(12):1556-64. doi:10.1177/1352458513504252 
68. Keytsman C, Eijnde BO, Hansen D, Verboven K, Wens I. Elevated cardiovascular risk factors in multiple sclerosis. Mult Scler Relat Disord (2017) 17:220-3. doi:10.1016/j.msard.2017.08.011

69. Bakshi R. Fatigue associated with multiple sclerosis: diagnosis, impact and management. Mult Scler (2003) 9(3):219-27. doi:10.1191/1352458503ms904oa

70. Kos D, Kerckhofs E, Nagels G, D'Hooghe MB, Ilsbroukx S. Origin of fatigue in multiple sclerosis: review of the literature. Neurorehabil Neural Repair (2008) 22(1):91-100. doi:10.1177/1545968306298934

71. Chervin RD. Sleepiness, fatigue, tiredness, and lack of energy in obstructive sleep apnea. Chest (2000) 118(2):372-9. doi:10.1378/chest.118.2.372

72. Hossain JL, Ahmad P, Reinish LW, Kayumov L, Hossain NK, Shapiro CM. Subjective fatigue and subjective sleepiness: two independent consequences of sleep disorders? J Sleep Res (2005) 14(3):245-53. doi:10.1111/j.13652869.2005.00466.x

73. Braley TJ, Chervin RD. Fatigue in multiple sclerosis: mechanisms, evaluation, and treatment. Sleep (2010) 33(8):1061-7. doi:10.1093/sleep/33.8.1061

74. Kushida CA, Nichols DA, Holmes TH, Quan SF, Walsh JK, Gottlieb DJ, et al. Effects of continuous positive airway pressure on neurocognitive function in obstructive sleep apnea patients: the Apnea Positive Pressure Long-term Efficacy Study (APPLES). Sleep (2012) 35(12):1593-602. doi:10.5665/ sleep. 2226

75. Canessa N, Castronovo V, Cappa SF, Aloia MS, Marelli S, Falini A, et al. Obstructive sleep apnea: brain structural changes and neurocognitive function before and after treatment. Am J Respir Crit Care Med (2011) 183(10):1419-26. doi:10.1164/rccm.201005-0693OC

76. Castronovo V, Canessa N, Strambi LF, Aloia MS, Consonni M, Marelli S, et al. Brain activation changes before and after PAP treatment in obstructive sleep apnea. Sleep (2009) 32(9):1161-72. doi:10.1093/sleep/32.9.1161

77. Zimmerman ME, Aloia MS. A review of neuroimaging in obstructive sleep apnea. J Clin Sleep Med (2006) 2(4):461-71.

78. Jackson ML, Howard ME, Barnes M. Cognition and daytime functioning in sleep-related breathing disorders. Prog Brain Res (2011) 190:53-68. doi:10.1016/B978-0-444-53817-8.00003-7

79. Bucks RS, Olaithe M, Eastwood P. Neurocognitive function in obstructive sleep apnoea: a meta-review. Respirology (2013) 18(1):61-70. doi:10.1111/j.1440-1843.2012.02255.x

80. Mehta V, Vasu TS, Phillips B, Chung F. Obstructive sleep apnea and oxygen therapy: a systematic review of the literature and meta-analysis. J Clin Sleep Med (2013) 9(3):271-9. doi:10.5664/jcsm.2500

81. Mattioli F, Stampatori C, Bellomi F, Scarpazza C, Capra R. Natalizumab significantly improves cognitive impairment over three years in MS: pattern of disability progression and preliminary MRI findings. PLoS One (2015) 10(7):e0131803. doi:10.1371/journal.pone.0131803

82. Mokhber N, Azarpazhooh A, Orouji E, Rao SM, Khorram B, Sahraian MA, et al. Cognitive dysfunction in patients with multiple sclerosis treated with different types of interferon beta: a randomized clinical trial. J Neurol Sci (2014) 342(1-2):16-20. doi:10.1016/j.jns.2014.01.038

83. Siegert RJ, Abernethy DA. Depression in multiple sclerosis: a review. J Neurol Neurosurg Psychiatry (2005) 76(4):469-75. doi:10.1136/jnnp.2004.054635

84. Harris M, Glozier N, Ratnavadivel R, Grunstein RR. Obstructive sleep apnea and depression. Sleep Med Rev (2009) 13(6):437-44. doi:10.1016/j. smrv.2009.04.001

85. Nilsagard Y, Gunn H, Freeman J, Hoang P, Lord S, Mazumder R, et al. Falls in people with MS - an individual data meta-analysis from studies from
Australia, Sweden, United Kingdom and the United States. Mult Scler (2015) 21(1):92-100. doi:10.1177/1352458514538884

86. Finlayson ML, Peterson EW, Cho CC. Risk factors for falling among people aged 45 to 90 years with multiple sclerosis. Arch Phys Med Rehabil (2006) 87(9):1274-9; quiz 87. doi:10.1016/j.apmr.2006.06.002

87. Cattaneo D, De Nuzzo C, Fascia T, Macalli M, Pisoni I, Cardini R. Risks of falls in subjects with multiple sclerosis. Arch Phys Med Rehabil (2002) 83(6):864-7. doi:10.1053/apmr.2002.32825

88. Hoang PD, Cameron MH, Gandevia SC, Lord SR. Neuropsychological, balance, and mobility risk factors for falls in people with multiple sclerosis: a prospective cohort study. Arch Phys Med Rehabil (2014) 95(3):480-6. doi:10.1016/j.apmr.2013.09.017

89. Stone KL, Ancoli-Israel S, Blackwell T, Ensrud KE, Cauley JA, Redline S, et al. Actigraphy-measured sleep characteristics and risk of falls in older women. Arch Intern Med (2008) 168(16):1768-75. doi:10.1001/archinte.168.16.1768

90. Stone KL, Ensrud KE, Ancoli-Israel S. Sleep, insomnia and falls in elderly patients. Sleep Med (2008) 9(Suppl 1):S18-22. doi:10.1016/ S1389-9457(08)70012-1

91. Chen PY, Chiu HT, Chiu HY. Daytime sleepiness is independently associated with falls in older adults with dementia. Geriatr Gerontol Int (2016) 16(7):850-5. doi:10.1111/ggi.12567

92. Ma J, Yao YJ, Ma RM, Li JQ, Wang T, Li XJ, et al. Effects of sleep deprivation on human postural control, subjective fatigue assessment and psychomotor performance. J Int Med Res (2009) 37(5):1311-20. doi:10.1177/147323000903700506

93. Robillard R, Prince F, Boissonneault M, Filipini D, Carrier J. Effects of increased homeostatic sleep pressure on postural control and their modulation by attentional resources. Neurophysiol Clin (2011) 122(9):1771-8. doi:10.1016/j.clinph.2011.02.010

94. Hayley AC, Williams LJ, Kennedy GA, HollowayKL, BerkM,Brennan-Olsen SL, et al. Excessive daytime sleepiness and falls among older men and women: cross-sectional examination of a population-based sample. BMC Geriatr (2015) 15:74. doi:10.1186/s12877-015-0068-2

95. Degache F, Goy Y, Vat S, Haba Rubio J, Contal O, Heinzer R. Sleep-disordered breathing and daytime postural stability. Thorax (2016) 71(6):543-8 doi:10.1136/thoraxjnl-2015-207490

96. Celle S, Annweiler C, Camicioli R, Barthelemy JC, Roche F, Beauchet O. Sleeprelated breathing disorders and gait variability: a cross-sectional preliminary study. BMC Pulm Med (2014) 14:140. doi:10.1186/1471-2466-14-140

97. Baillieul S, Perennou D, Marillier M, Pepin JL, Verges S, Wuyam B. Impaired control of gait in patients with severe obstructive sleep apnea is reversed by continuous positive airway pressure treatment. Ann Phys Rehabil Med (2016) 59s:e118-9. doi:10.1016/j.rehab.2016.07.268

Conflict of Interest Statement: $\mathrm{HH}$ and AK do not have any conflicts to declare. DE has a Cooperative Research Centre Project Grant which is cosupported by the Australian Government and an industry partner (Oventus Medical) and serves as a consultant for Bayer.

Copyright (c) 2018 Hensen, Krishnan and Eckert. This is an open-access article distributed under the terms of the Creative Commons Attribution License (CC BY). The use, distribution or reproduction in other forums is permitted, provided the original author(s) or licensor are credited and that the original publication in this journal is cited, in accordance with accepted academic practice. No use, distribution or reproduction is permitted which does not comply with these terms. 